\title{
A MODIFIED AMMONIUM MOLYBDATE SOLUTION.
}

\author{
By A. L. Winton.
}

Received March 18, 1896.

\HEN phosphoric acid is determined by the molybdate method, it is a common practice to add fifteen grams of ammonium nitrate to the phosphate solution and heat before adding ammonium molybdate. By this means the separation of the yellow precipitate is greatly facilitated and the time of digestion shortened. But to dissolve this nitrate requires some time and very greatly reduces the temperature of the solution so that special care is necessary in heating it subsequently. In the laboratory of this station it has been our practice to simplify the process by omitting the separate addition of ammonium nitrate and using a molybdic solution containing the requisite quantity of the salt. Such a solution may be prepared according to the following formula:

I. Dissolve Iooo grams of molybdic acid in $4 \mathrm{I} 60 \mathrm{cc}$. of a mixture of one part of concentrated ammonia water (sp. gr. o.go) and two of water.

II. Dissolve 5300 grams of ammonium nitrate in a mixture of $6250 \mathrm{cc}$. of concentrated nitric acid (sp. gr. I.4) and $3090 \mathrm{cc}$. of water.

Add I to II slowly with constant stirring. Allow to stand for a few days in a warm place and decant off the clear liquid.

This solution has the same proportion of ammonium molybdate and free nitric acid as the molybdic solution of Fresenius, but differs from the latter in that fifty cc. contain fifteen grams more of ammonium nitrate. We have prepared the solution so as to contain this proportion of the salt because in the routine analysis of fertilizers in the station laboratory fifty cc. are most commonly employed. This quantity in our experience is usually sufficient for the precipitation of the soluble, insoluble or total phosphoric acid of mixed fertilizers in solutions representing four-tenths, two, and five-tenths grams respectively of the material.

In no case ought less than fifty cc. be used, for otherwise there may not be enough ammonium nitrate present for the perfect separation of the yellow precipitate. When a larger quan- 
tity of molybdic solution is required, as, for example, in the determination of total phosphoric acid in ground bone, bone black, Thomas slag, etc., it may be added without fear that the larger quantity of ammonium nitrate contained in it will in any way interfere with the process. If, however, it is thought desirable, a special molybdic solution containing fifteen grams of added ammonium nitrate to every seventy-five or $100 \mathrm{cc}$. of the liquid may be prepared for such cases.

CONNECTICUT AGRICULTURAL EXPERIMENT STATION.

New HAVEN, CONS.

\section{ON THE ESTIMATION OF SULPHUR IN PYRITES.}

By Thomas S. GLadDing. Received March 30, 1896 .

I the October (1895) number of this Journal, Dr. Lunge continues his discussion of the estimation of sulphur in pyrites. He presents no new experimental support of his position. $\mathrm{He}$ indirectly accuses me of having published a "private" communication without the sanction of the writer, Prof. Richards. In reply I will say that the words of Prof. Richards were published by myself, not only with full permission, but after a careful revision of the same by their author. Had Dr. Lunge addressed a note to Prof. Richards or to myself, he would have been saved from making a most unkind and needless accusation.

While Lunge attempts no further support of his position by chemical experiment, he makes the claim that any occlusion of barium chloride that occurs is compensated for by the solubility of barium sulphate in the acid liquor of precipitation. In his own words "my claim has been that my method by compensation of unavoidable errors, gives correct results."

I have investigated this claim of Lunge's, as far as it applies to the occlusion of barium chloride in his method, in the following manner: I have had one of our assistants repeat the work with chemically pure sulphate of ammonia, using two grams in each case. making comparison precipitations with a ten per cent. solution of barium chloride, the first by adding the barium chloride solution drop by drop from a burette, the second by sudden addition from a small beaker in which it had been brought to the boiling point. The results were as follows : 